Journal of Learning and Development Studies (JLDS)

DOI: 10.32996/jlds

Journal Homepage: www.al-kindipublisher.com/index.php/jlds

\title{
Online language Classes: Perceptions and Challenges of Prospective Language Teachers
}

\author{
Nurziana U. Hamsan \\ College of Teacher Education, Western Mindanao State University \\ Corresponding Author: Nurziana U. Hamsan, E-mail: nurzianahamsann@gmail.com
}

\begin{abstract}
ARTICLE INFO
ABSTRACT

Received: August 08, 2021

Accepted: September 30, 2021

Volume: 1

Issue: 1

DOI: $10.32996 / j l d s .2021 .1 .1 .7$

The COVID-19 pandemic has caused many activities to be halted including education. Educational institutions are now closed and operating online to ensure the safety of the students and the teachers. Students are now learning online and modular mode. Thus, it has caused the students and teachers to encounter bumps in learning. Hence, this led the researcher to find out and examine the perceptions and challenges that

\section{KEYWORDS}

Online learning, challenges, prospective language teachers, perceptions, pandemic prospective language teachers experience when learning online. The researcher utilized the thematic analysis method to reveal the perceptions and challenges experienced by prospective language teachers in online learning. The data for this study were obtained from the interviews that were conducted with the respondents. It was revealed that there were a number of challenges that the respondents experienced which include poor internet connection, physical distractions, lack of motivation and power interruptions.
\end{abstract}

Published by Al-Kindi Center for Research and Development, London, United Kingdom

Copyright (c) the author(s). This open access article is distributed under a Creative Commons Attribution (CC-BY) 4.0 license (https://creativecommons.org/licenses/by-nc-nd/4.0/)

\section{Introduction}

Learning usually takes place in a classroom setting where the teacher teaches in front with his notes and his markers or chalks to write on the board, and with having the students listen to the lesson on their chairs. In other words, the traditional face to face learning. However, this classroom setting was put to a halt due to the pandemic that the world is experiencing. Learning online has been the new norm since the pandemic has started. More than a year ago, the traditional face to face learning was replaced by online and modular learning.

According to Howlett et al. (2009), online education is defined as the usage of electronic technology and media to support, deliver and enhance the teaching-learning process, and it includes communication using online content between the teacher and the students. Relative to this, Nwankwo (2015) defines online learning as a form of education where it is through the Internet that school contents are accessed, and discussions are done virtually. Also, assignments and teachers' feedbacks are electronically given.

With the rise of COVID-19, the result was the shutdown of schools all around the world and this gave birth to most schools preferring to have online learning as their schools' learning modality. The traditional face to face classes was substituted by the online learning modality. This sudden transition from the traditional face to face to online learning has produced quite a few bumps for many people, it caused educational institutions to encounter challenges (Hong \& Sol, 2020). One of those is that when online learning was introduced, students were not ready for online education (Dhawan, 2020). In a similar vein, Coman et al. (2020) states in their study that students as well as teachers were not yet ready and prepared for the new learning modality due to the sudden shift from traditional to online learning and also because of the fact that teachers and students needed to adapt to changes in the teaching-learning process (Nugroho, Ilmiani, \& Rekha, 2020). Moreover, Beggs (2000, cited in Ghavifekr et al., 2016) found in his study that having lack of training was named as one of teachers' challenges in learning online. Another difficulty is that when the pandemic started, most students and teachers needed to rely on online learning, and challenges like poor internet connectivity were encountered. In line with this, Dhawan (2020) posits that aside from the unavailability of tools for online class, poor or no internet connection is one of the barriers in online learning for the students and the teachers as well.

Furthermore, many studies have been conducted regarding the perceptions and challenges of teachers, or the students on online learning. Nugroho, Ilmiani, \& Rekha (2020), and Rahman (2020) studied the challenges of EFL teachers with regards to online teaching in the pandemic. In line with this, Rosalina, Nasrullah and Elyani (2020) studies on the same context, focusing on the 
challenges that teachers have in online learning during the pandemic and their strengths and weaknesses based on the teachers' perceptions.

Having to mention all the studies beforehand, it was observed that most of the studies conducted are focused on teachers' and other students' perceptions and challenges (Dhawan, 2020; Coman et al., 2020; Nugroho, Ilmiani, \& Rekha, 2020; Hong \& Sol, 2020; Besser, Flett \& Hill, 2020; \& Khan et al., 2020). However, despite having all these studies conducted, it was also observed that there were no studies that aimed to have prospective language teachers as respondents. Therefore, this study is conducted mainly to fill the gap of the previous studies and examine the perceptions and challenges encountered in learning online with having, specifically, prospective language teachers as respondents. Moreover, this study reveals the challenges and perceptions of prospective language teachers in learning online.

\subsection{Research Questions}

This study aimed to examine the perceptions and challenges of prospective language teachers in online learning. Specifically, the paper pursued to answer the following questions:

1. What are the perceptions of prospective language teachers toward online classes?

2. What are the perceptions of prospective language teachers toward online classes?

\section{Review of Related Literature}

\subsection{Online Learning}

The pandemic has caused most people to do things online, wherein the people were forced to have classes, office work, and meetings online and even shopping is done online. This is because the virus that continuously spreading is hindering most people to do things like the old way. In line with this, online learning is now a thing or more like the most necessary thing to do for students and teachers to be safe from the unseen enemy. Dhawan (2020) described online learning as a learning experience that has an environment that includes the utilization of various devices like laptops, mobile phones, tablets and other useful devices for synchronous and asynchronous classes. In a similar way, Fry (2001) defined online learning as a learning experience that uses the internet and technologies to produce materials to be used in the teaching-learning process. In simple terms, online learning is a learning experience that happens online or virtually that uses technological devices and also requires the use of the internet. With the spread of COVID-19, the use of this learning environment is essential.

However, even though this is the most essential and necessary thing to be done to continue education, it still cannot cover the fact that there are numbers of challenges that are experienced by students and teachers in learning online. Numbers of studies have been conducted to investigate and examine the perceptions and challenges experienced by teachers and students in online learning (Kufi, Negassa, Melaku, \& Mergo, 2020; Dhawan, 2020; Gilbert, 2015; Coman et al., 2020; Nugroho, Ilmiani, \& Rekha, 2020; Belgica, Calugan, Dumo \& Simber, 2020; Heng \& Sol, 2020; Besser, Flett \& Hill, 2020; \& Khan et al., 2020).

\subsection{Perceptions towards Online Learning}

The COVID-19 outbreak has caused many changes in people's lives, also in teaching-learning process. This sudden shift of learning mode from traditional face to face to online mode of learning has earned various perceptions and views from the people involved like the teachers and the students. The study of Burac et al. (2019) found that even when there are challenges encountered by the students in online classes, they still appeared to have positive attitude towards online learning. Similarly, Allo (2020) revealed that students had positive attitudes towards online learning, for the reason that it is a mode of learning that is convenient to be used during times like this. This implies that students see online learning as a useful learning modality in this time of pandemic where learning in the physical classroom is not advisable. In line with this, Demuyakor (2020) found that students perceived having the new learning modality, online learning, as very useful, and most students agreed that learning online was effective.

It can be noticed that there are a number of studies that reveals that students are satisfied with their experiences in the new mode of learning. However, there were also studies that showed students' negative response to the new learning modality. Yang \& Cornelius (2004) found that students had negative perceptions toward online learning, and it is because of the absence of face to face interaction between the students and the teachers. Same results were found in the study of Adnan and Anwar (2020), it was revealed that lack of interaction with the teachers during online classes was included in the challenges that the students came in contact with.

On the other hand, since the shift from traditional to online learning was sudden because of the pandemic, findings from the study of Aboagye, Yawson, and Appiah (2020) reveals that students were not ready to take online classes because of the challenges that might be faced when learning online. In line with this, Agung, Surtikanti, and Quinones (2020) states that in terms of the style of teaching and learning in the online modality, students and teachers were not prepared to learn and teach online. 


\subsection{Challenges in Online Learning}

Online education has already been there even before there was a pandemic, however, it was the pandemic that caused online education to be prominent in this time. Because of the pandemic, educational institutions were forced to have classes online instead of having it face to face to ensure the safety from the virus of the people involved. With having classes online, number of challenges that students and teachers experience when learning or teaching online are realized.

Dhawan (2020) revealed that there are challenges or difficulties that are experienced in reliance to modern technology. Problems in downloading, login errors and audio-video problem are its examples. Similarly, Ramajunam (2002) reveals in their study that one of the challenges experienced is the lack of technological skills those who are situated in rural areas. This implies that students must be competent in using technological tools since it is what is required when learning online. Technical difficulties are the hardest to solve (Coman, 2020), it is one of the challenges that are encountered and are difficult to give solutions to. Moreover, Adedoyin and Soykan (2020) states that various challenges were created due to the abrupt transition from traditional to online learning. In view of this, Agung, Surtikanti, and Quinones (2020) found in their study that challenges regarding internet connection were experienced by students in learning online wherein connection to the Internet was unstable, and other students had no connection at all.

\section{Method}

\subsection{Research Design}

The present study purposes to examine the perceptions of the prospective language teachers and their challenges in learning online. A descriptive approach was employed by conducting semi-structured interviews to gather data needed for the study. Prospective language teachers' perceptions and challenges in online classes were examined using the descriptive research approach. Nassaji (2015) describes descriptive research as one that involves describing a phenomenon and its characteristics. This research design is used to examine the perceptions and the challenge that are experienced by prospective language teachers in their online learning. On the other hand, semi-structured interviews are those that involves dialogue between the respondent and the researcher, which also consists the interview protocol, follow-up questions, probing and comments (DeJonckheere \& Vaughn, 2019).

\subsection{Participants}

The current study had respondents who are prospective language teachers. 7 students taking up Bachelor of Secondary Education major in English, including 1 male and 6 females who were enrolled in the same university. The age range of the respondents were between 21 and 22 years old3. The participants of this study participated voluntarily upon invitation, and were included using these criteria; (1) currently enrolled and learning online, (2) prospective language teachers and (3) must be in their 3rd year of college education.

\subsection{Instruments and data collection}

This study employed semi-structured interviews in all the 7 participants. DeJonckheere \& Vaughn (2019) states that semi-structured interviews are those that involves dialogue between the respondent and the researcher, which also consists the interview protocol, follow-up questions, probing and comments. Considering the situation in this pandemic, the interviews were done through phone calls in accordance to the health protocol of the state and for the safety of both the respondents and the researcher. Prior to the interview, the questions were reviewed and evaluated to make sure it matches the research questions.

The researcher requested for the respondents' approval for the interview. Transcriptions were also produced by the researcher. Moreover, consent and approval for the interview were asked prior to the data collection, the interviews were scheduled considering the time convenient for each of the respondent. Furthermore, the interviews lasted for 10-15 minutes in each of the respondents, also, the respondents were interviewed separately. On the other hand, audio recordings were done for the purpose of data collection.

\section{Findings and Discussion}

In the first part of the interview, the participants were asked about their experiences in learning online.

The following are excerpts from the interview:

\section{Participant 2}

"My online learning experiences, I can say it's a bit difficult and tiring. I can say that it's quite and challenging and difficult."

\section{Participant 4}

"my experiences in this new learning modality, it's interesting and also challenging... it is challenging due to some difficulties that I have encountered in this new learning modality." 


\section{Participant 7}

"my online learning experience is more of a challenge than a good experience for me, because based on my experience while learning during online session, I can say that I am not deeply motivated to learn, since online learning limits the interaction between the teacher and the student. Wherein the class sessions are less engaging."

The data from the excerpts shows that there were challenges that were experienced by the participants of the study in their online classes. The pandemic has caused many things to be stopped, including the face to face classes, hence why online classes are now the mode of learning of the students. And the reason why challenges were encountered while learning is conducted online.

Table 1: Prospective language teachers' perceptions in online language classes

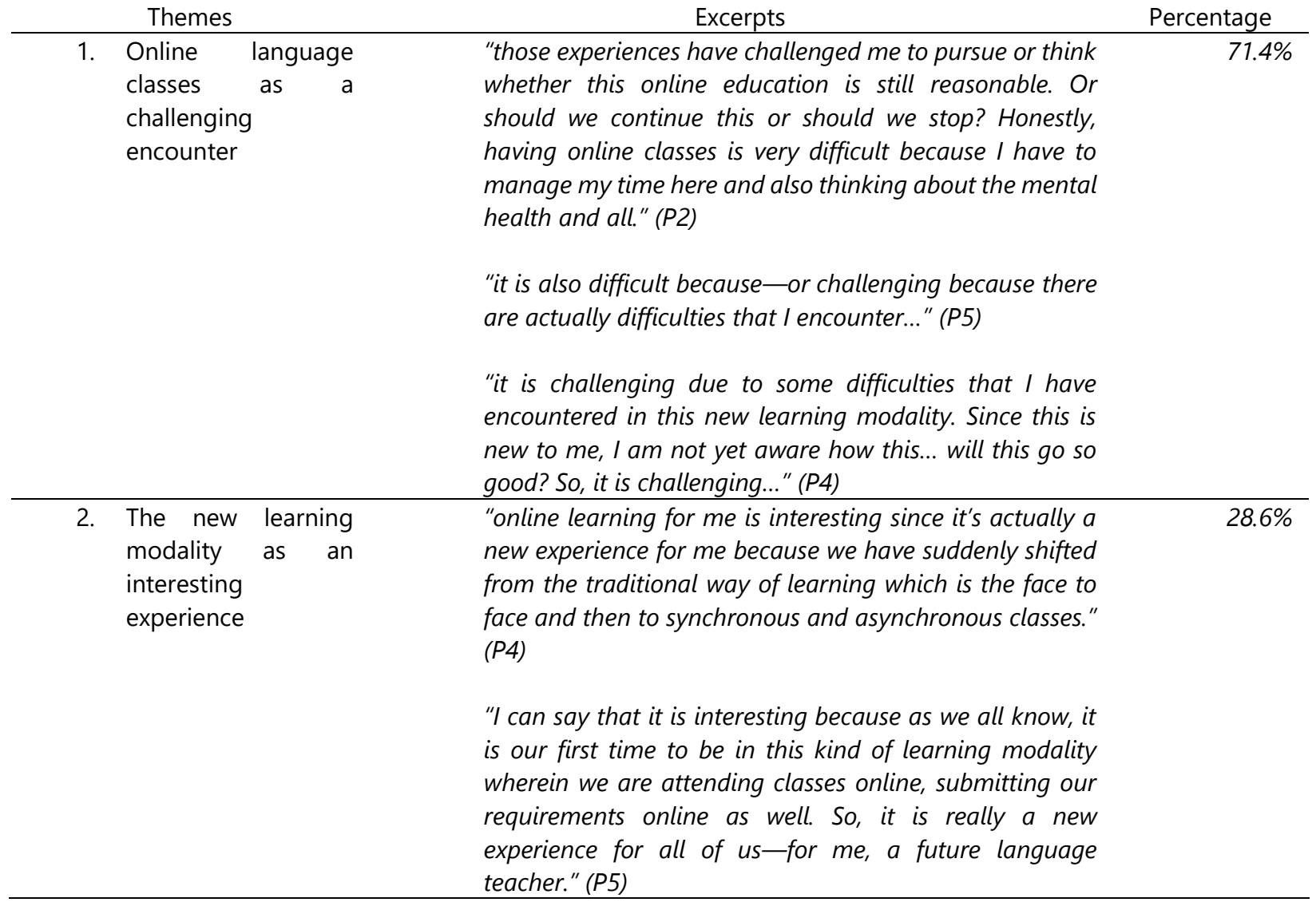

Table 1 presents the perceptions of prospective language teachers towards learning online. Most of them answered that online learning is challenging experience and an interesting one because it is a new learning environment for them.

In reference to the results captured from the data analysis, most of the respondents answered that online classes are challenging and difficult, the first response from one of the respondents stated that online classes are challenging because there are difficulties and challenges that they encountered while they were having online classes. Moreover, other respondents say that it is challenging thinking about how online classes affects their mental health and the difficulty of time management.

The following excerpts are presented to support the claim:

\section{Participant 2}

"those experiences have challenged me to pursue or think whether this online education is still reasonable. Or should we continue this or should we stop? Honestly, having online classes is very difficult because I have to manage my time here and also thinking about the mental health and all."

\section{Participant 4}


"it is challenging due to some difficulties that I have encountered in this new learning modality. Since this is new to me, I am not yet aware how this... will this go so good? So, it is challenging..."

Another, based on the responses of the respondents, it was revealed that the new learning modality-online learning, is an interesting experience for them since it is a new learning environment and a new way for them to learn.

The excerpts below are presented as evidence:

\section{Participant 4}

"online learning for me is interesting since it's actually a new experience for me because we have suddenly shifted from the traditional way of learning which is the face to face and then to synchronous and asynchronous classes."

\section{Participant 5}

"I can say that it is interesting because as we all know, it is our first time to be in this kind of learning modality wherein we are attending classes online, submitting our requirements online as well. So, it is really a new experience for all of us-for me, a future language teacher."

In can be inferred that the respondents of the study mostly answered that online classes are a challenging yet interesting experience for them. This is due to the fact that it is a new learning environment, so there are difficulties that they encounter while they are in their online learning, at the same it is interesting because it is a new learning mode and it is their first time to be in this kind of learning modality.

The result of the study shows the different perceptions of prospective language teachers on online language learning. Online classes are challenging due to the difficulties that are encountered by the students when attending classes online. In line with this, Dhawan (2020) states that difficulties that are encountered by students in online classes may slow down the learning process of the students. This implies that if there are difficulties or challenges that the students experience in online classes, it might hinder their learning process. Supporting, Belgica et al. (2020) states that the sudden shift from traditional to online learning has caused students to experience difficulties. On the other hand, it was also revealed that the respondents find learning in online classes interesting for the reason that it is a new learning environment for them.

Table 2: Prospective Language Teachers' Challenges on Online Language Classes

\begin{tabular}{|c|c|c|c|}
\hline Themes & & Excerpts & Percentage \\
\hline 1. & $\begin{array}{l}\text { Dealing with the Awful } \\
\text { Internet Connection }\end{array}$ & $\begin{array}{l}\text { "Our internet connection is notoriously known for being } \\
\text { erratic... my internet is not allowing me to get into my } \\
\text { classes and I guess it's also a bit applicable to my other } \\
\text { friends because some of them are in areas that are not } \\
\text { really great with the internet connection. So, I think it's one } \\
\text { commonality... me and my friends have in common. But } \\
\text { mostly, me." (P1) }\end{array}$ & $71.4 \%$ \\
\hline & & $\begin{array}{l}\text { "...number } 1 \text { would be the internet connection... because } \\
\text { when the internet connection is really bad, sometimes } \\
\text { because of the weather, sometimes because of the network } \\
\text { itself...they have problem with their network. With the } \\
\text { internet connection, I cannot-I mean sometimes I get } \\
\text { disconnected from our classes..." (P2) }\end{array}$ & \\
\hline & & $\begin{array}{l}\text { "I am also in the rural area, even though I am just in } \\
\text { Zamboanga City, here in our area, the internet connection } \\
\text { is not really stable and I don't have wifi connection, I also } \\
\text { rely and depend on mobile data and it's not always stable... } \\
\text { when I am having my synchronous classes or when the } \\
\text { teacher is having a video conference or presentations, } \\
\text { discussions. And here I am, I cannot join the class. Or I can } \\
\text { join but then gets disconnected later and then join then get } \\
\text { disconnected." (P4) }\end{array}$ & \\
\hline
\end{tabular}


2. Lack of motivation "I get in my class, I don't have motivation. So, I cannot put my mental state at a certain point... So, you need to... you need to... you need to focus, you need to motivate yourself." (P1)

"based on my experience while learning during online session, I can say that I am not deeply motivated to learn, since online learning limits the interaction between the teacher and the student..." (P7)

3. Physical distractions "the background noises also in our area, the cries of the during online classes baby, and the animals. They are actually interrupting my class; I cannot understand what the teacher is saying because of the background noises that is all around me." (P5)

"The other challenge that I have experienced is the background noises in my surroundings. Even inside my room there are still noises coming from my neighbors such as barking, noise from the vehicles and also noise from a house being constructed or renovated in the past last few weeks." (P6)

4. Unforeseen power "there is a power outage in our area... these power interruptions are actually frustrating, really. For example, since I am using a wifi-prepaid wifi, there are times wherein there are power interruptions and then suddenly I get disconnected from the class. And what I have to do is I still have to buy a load to use my mobile data instead of the wifi." (P5)

"the last challenge that I will share is about the power interruption... it's really a barrier for me to attend my online classes just like what I have mentioned. When there is power interruption I just use my mobile data but sometimes my mobile data has poor signal, that's why I cannot focus on the meeting or I might miss an important discussion or announcement." (P7)

5. Difficulty in "Here in our area, the internet connection is not really stable
understanding lessons and I don't have wifi connection, I also rely and depend on due to poor internet mobile data and it's not always stable. It really affects me connectivity specially when I am having my synchronous classes or when the teacher is having a video conference or presentations, discussions. I cannot join the class. Or I can join but then gets disconnected later and then join then get disconnected. It's very inconvenient for me because I cannot understand the lesson very well." (P4)

"this internet connectivity issue, like most of the time the internet is actually very slow here in our area. Every time I try to attend online classes, there are instances wherein the internet is really slow... during class discussions, there are times wherein the teacher gets choppy or the internet will interrupt my connection. So, there are times I cannot hear what the teacher is saying, so, I cannot understand and comprehend well what is the discussion all about." (P5) 
6. Lack of understanding "sometimes I can't understand the lectures or the subject

$14.3 \%$ of the lecture due to because usually some of the professors do not... they just teachers not teaching leave activities. All we have to do is to comply that and then what I personally expect is that it will be discussed however it was not the result." (R6)

Table 2 shows the challenges that the respondents encountered in learning online. Six challenges were identified by the respondents in learning online, hence, six themes were created as well.

Based on the results of the data analysis, the erratic internet connection was cited as one of the challenges that the respondents experienced in learning online, wherein the respondents experience bad connection while attending online classes and then leads to being absent from the class. The poor internet connection has affected students' online learning, students in or not in rural areas. In connection, Dhawan (2020) states that encountered difficulties in online classes may contribute to slow learning process of the students.

Moreover, one of the respondents answered that due to the poor internet connection, comprehension of the lesson is hard for the reason that poor internet connection results to having bad audio wherein the students cannot hear the teacher discussing and presenting the lessons.

The following excerpt is presented as evidence:

\section{Participant 5}

"...during online classes, when there is a discussion or there will be a presentation, I am having difficulties and I actually struggle in comprehending what the discussion is all about... the teacher gets choppy on my end. But there are also times wherein there were really no voices that will be heard on my end. The connection really just disappears, like that..."

The lack of motivation of the respondents was cited as one of the challenges they experience in learning online. Attending online classes made the respondents less motivated to do and finish tasks, because of this they lose focus in the discussions they have in online classes. Serwatka (2005) revealed that one of the main reasons for students' less understanding of the lessons being taught in their online courses is the insufficiency or lack of motivation in learning.

The excerpts below are presented as evidence:

\section{Participant 1}

"I get in my class, I don't have motivation. So, I cannot put my mental state at a certain point... So, you need to... you need to... you need to focus, you need to motivate yourself."

\section{Participant 2}

"It is really difficult and I do not have the drive or... drive to continue or to finish some of the assignments that were given because... it is taking a toll in this online class."

Furthermore, the less interaction between the teachers and the students was also listed as one that causes lack of motivation for the students. Yang \& Cornelius (2004) the absence of face to face interaction between the students and the teachers caused the students to have negative perceptions toward online classes.

The excerpt below is presented as evidence:

\section{Participant 7}

"based on my experience while learning during online session, I can say that I am not deeply motivated to learn, since online learning limits the interaction between the teacher and the student..."

Another challenge that were identified is the physical distraction during online classes. Because of the environment or the nature where the respondents are learning and attending, it affects their concentration in class. Physical distractions during online learning is cited as one of the challenges that most the respondents of this study experienced. The noises around the learning area is one of the distraction that the respondents answered from the interview.

Below are the excerpts: 


\section{Participant 5}

"the background noises also in our area, the cries of the baby, and the animals. They are actually interrupting my class; I cannot understand what the teacher is saying because of the background noises that is all around me."

\section{Participant 6}

"The other challenge that I have experienced is the background noises in my surroundings. Even inside my room there are still noises coming from my neighbors such as barking, noise from the vehicles and also noise from a house being constructed or renovated in the past last few weeks."

According to one of the respondents, the noises from the people inside the house also contributes to the distractions that are encountered when attending online classes. The respondent cited this as one of the challenges experienced in learning online.

\section{Participant 3}

"sometimes there are disturbances like when your mother calls you when you're in your online class. You have to attend both."

Moreover, the unexpected power outages in some areas was also identified as one of the challenges that the respondents encountered when learning online. These unforeseen power interruptions affect the learning of the students in online classes, for the reason that the internet connectivity of the respondents is dependent on the electricity, so when the power is out the internet is also out.

The excerpts below support this claim:

\section{Respondent 5}

"there is a power outage in our area... these power interruptions are actually frustrating, really. For example, since I am using a wifi-prepaid wifi, there are times wherein there are power interruptions and then suddenly I get disconnected from the class. And what I have to do is I still have to buy a load to use my mobile data instead of the wifi."

\section{Respondent 7}

"the last challenge that I will share is about the power interruption... it's really a barrier for me to attend my online classes just like what I have mentioned. When there is power interruption I just use my mobile data but sometimes my mobile data has poor signal, that's why I cannot focus on the meeting or I might miss an important discussion or announcement."

Another challenge encountered by the respondents is the difficulty in understanding lessons due to poor internet connectivity. Through the interviews that was conducted, two of the respondents answered that they were having difficulty in understanding the lessons being taught because of the poor connection that they have. The poor internet connectivity that students experience really affects their learning.

These were drawn from the excerpts below:

\section{Participant 4}

"Here in our area, the internet connection is not really stable and I don't have wifi connection, I also rely and depend on mobile data and it's not always stable. It really affects me specially when I am having my synchronous classes or when the teacher is having a video conference or presentations, discussions. I cannot join the class. Or I can join but then gets disconnected later and then join then get disconnected. It's very inconvenient for me because I cannot understand the lesson very well."

\section{Participant 5}

"this internet connectivity issue, like most of the time the internet is actually very slow here in our area. Every time I try to attend online classes, there are instances wherein the internet is really slow... during class discussions, there are times wherein the teacher gets choppy or the internet will interrupt my connection. So, there are times I cannot hear what the teacher is saying, so, I cannot understand and comprehend well what is the discussion all about."

Lastly, lack of comprehension was mentioned one of the challenges experienced in online learning. One of the respondents said that this is of the challenges due to the fact that some teachers do not teach the lesson so, there is less understanding of the lesson. There are a lot of things that students and teachers experience in learning and teaching online, there may be reasons why teachers or students do the things they do. 
The excerpt below supports this idea:

\section{Participant 6}

"sometimes I can't understand the lectures or the subject because usually some of the professors do not... they just leave activities. All we have to do is to comply that and then what I personally expect is that it will be discussed however it was not the result."

The result of the study shows that a lot of challenges are encountered and experienced by prospective language teachers in online classes. The erratic internet connection was cited as the number one challenge that the respondents have, most of them answered that poor internet connectivity is one of the challenges they encounter in learning online. Dhawan (2020) cites poor internet connectivity as one of the barriers in learning online aside from the other factors he mentioned. Similarly, Coman et al. (2020) listed poor internet connection as one of the problems experienced by students especially those situated in rural areas. Besides that, lack of motivation is also included in the list. Some of the respondents answered that they were unmotivated to learn and finish tasks online, one of them answered that this is due to the less interaction between students and teachers, also students and students. According to the studies of Aragon and Johnson (2008) and Serwatka (2005), lack of motivation is one of the main reasons for students' less grasp of online courses. This means that when students are less motivated in the process of learning, they are less likely to learn and understand the concepts being taught in online classes. Supporting this, Chaney (2001) states that lack of motivation can lead to being lost in the course that one the student is currently learning.

Learning online has its fair share of challenges. In addition to the abovementioned matters, physical distractions were also included in the list of the challenges that the respondents have. Majority of the students attends online classes at home, so physical distractions are really inevitable. Be it distractions from the people around us, the noises heard from the vehicles passing or the sound of the animals that are heard in video meetings during online classes. On the other hand, aside from poor internet connection, another technical difficulty is identified which is power interruption.

Lastly, lack of understanding due to the teachers not teaching the lesson, also because of the poor connection that students have when having online classes were also listed. In the study of Gilbert (2015), it was found that lack of interaction between the teachers and students was one of the challenges identified and lack of instructions from the teachers as well. Due to these reasons, students' comprehension of the subject matter was less than what was expected.

\section{Conclusion and Recommendation}

The present study aimed at examining the perceptions and the challenges that prospective language teachers experience in learning in the online modality. It was evident that there were quite a few number of challenges identified through the investigation conducted by the researcher. Aside from the challenges encountered by the respondents, their perceptions toward online classes were also identified.

It can be inferred that the respondents' perceptions toward online classes are; one, it is a challenging experience because of the difficulties and the challenges resulted from learning online; last, online classes are an interesting encounter due to the fact that it introduced students to a new learning environment and new learning modality. On the other hand, the challenges that was named in the study was the erratic internet connection, lack of motivation, physical distractions, technical difficulties and the lack of interaction between teachers and learners which resulted to the lack of understanding of the lesson.

Therefore, it is recommended that aside from the online learning materials that teachers make available for online learning, they should also make materials that will cater students that has difficulties in accessing those learning materials. Furthermore, students should also exert effort for them to be able to conquer the challenges they encounter in learning online.

\section{References}

[1] Aboagye, E., Yawson, J., \& Appiah, K. (2020). COVID-19 and E-Learning: The challenges of students in tertiary institutions. Social Education Research, 2(1), 1-8.

[2] Adedoyin, O. \& Soykan, E. (2020). Covid-19 pandemic and online learning: The challenegs and opportunities. Interactive Learning Environment, 1-13.

[3] Adnan, M. \& Anwar, K. (2020). Online learning amid the COVID-19 pandemic: Students' perspectives. Journal of Pedagogical Sociology and Psychology, 2(1), 45-51.

[4] Agung, A., Surtikanti, M., \& Quinones, C. (2020). Students' perceptions of online learning during COVID-19 pandemic: A case study on the English students of STKIP Pamane Talino. Journal of Sciences and Humanities, 10(2), 2088-2262.

[5] Allo, M. D. (2020). Is the online learning good in the midst of Covid-19 pandemic? The case of EFL teachers. Jurnal Sinestesia, 1(1), 1-10.

[6] Aragon, S. \& Johnson, E. (2008). Factors influencing completion and noncompletion of community college online courses. The American Journal of Distance Learning, 22, 146-158.

[7] Belgica, C.,Calugan, J., Dumo, J.,\& Simber, L. (2020). Online distance learning: Thematic study on the challenges faced by Educare College Inc. primary pupil. Advanced Research in Education, Teaching \& Learning, 1-15. 
[8] Besser, A., Flett, G., \& Hill, V. (2020). Adaptability to a sudden transition to online learning during the COVID-19 pandemic: Understanding the challenges for students. Scholarship of Teaching and Learning in Psychology, 1-21.

[9] Burac, M., Fernandez, J., Cruz, M., \& Dela Cruz, J. (2020). Assessing the impact of e-learning system of higher education institution's instructors and students. The International Conference on Information technology and Digital Applications, 1-8.

[10] Chaney, E. G. (2001). Web-based instruction in a rural high school: A collaborative inquiry into its effectiveness and desirability. NASSP Bulletin, 85(628), 20-35.

[11] Coman, C., Tiru, L., Schmitz, L., Stanciu, C. \& Bularca, M. (2020). Online teaching and learning in higher education during the Coronavirus pandemic: Students' perspective. Sustainability, 12, 2-24.

[12] DeJonckheere, M. \& Vaughn, L. (2019). Semistructured interviewing in primary care resaerch: A balance of relationship and riguor. Family Medicine and Community Health, 1-8.

[13] Dhawan, S. (2020). Online learning: A panacea in the time of COVID-19 crisis. Journal of Education Technology, 49(1), 5-22.

[14] Fry, K. (2001). E-learning markets and providers: Some issues and prospects. Education + Training, 43(5), 233-239.

[15] Ghavifekr, S., Kunjappan, T., Ramasamy, L., \& Anthony, A. (2016). Teaching and learning with ICT tools: Issues and challenges from teachers' perceptions. Malaysian Online Journal of Educational Technology, 4(2), 38-57.

[16] Gilbert, B. (2015). Online learning revealing the benefits and challenges. Fisher Digital Publication, 4, 1-28.

[17] Heng, K. \& Sol, K. (2020). Online learning during COVID-19: Key challenges and suggestions to enhance effectiveness. Cambodian Education Forum, 1-15.

[18] Howlett, D., Vincent, T., Gainsborough, N., Fairclough, J., Taylor, N., Cohen, J., \& Vincent, R. (2009). Integration of a case-based online module into an undergraduate curriculum: What is involved and is it effective? E-Learning, 6(4), 372-384.

[19] Kufi, E., Negassa, T., Melaku, R., \& Mergo, R. (2020). Impact of corona pandemic on educational undertakings and possiblle breakthrough mechanisms. BizEcons Quarterly, 11, 3-14.

[20] Nugroho, A., Ilmiani, D., \& Rekha, A. (2020). EFL Teachers' challenges and insights of online teaching amidst global pandemic. Metathesis: Journal of English Language Literature and Teaching, 4(3), 277-291.

[21] Nwankwo, A. A. (2015). Students' learning experiences and perceptions of online course content and interaction. Walden University ScholarWorks.

[22] Ramanujam, P. R. (2001). Distance open learning in the developing Asian countries: Problems and possible solutions. Internationa Institute for Educational Planning, 1-36.

[23] Rosalina, E., Nasrullah, \& Elyani, E. (2020). Teacher's challenges towards online learning in pandemic era. Linguistics, Literature and English Teaching Journal, 10(2), 71-88.

[24] Serwatka, J. A. (2005). Improving retention in distance learning classes. International Journal of Instructional Technology \& Distance Learning, 2(1), 59-64.

[25] Yang, Y. \& Cornelius, L. (2004). Students' perceptions towards the quality of online education: A qualitative approach. Association for Educational Communications and Technology, 861-877.

[26] Yusuf, B. \& Ahmad, J. (2020). Are we prepared enough? A case study of challenges in online learning in a private higher learning institution during the Covid-19 outbreaks. Advances in Social Science Research Journal, 7(5), 205-212. 